Vol. 2, No. 1, Juni 2021

\title{
SPEKTA
}

Jurnal Pengabdian Kepada Masyarakat : Teknologi dan Aplikasi

Journal homepage :

http://journal2.uad.ac.id/index.php/spekta

\section{PENDAMPINGAN MASYARAKAT BERBASIS INFORMATION TECHNOLOGY (IT) PADA PIMPINAN RANTING MUHAMMADIYAH BANGUNJIWO BARAT DI TENGAH PERSAINGAN MASYARAKAT EKONOMI ASEAN}

\author{
Ali Maksum ${ }^{1, *}$, Oki Wijaya ${ }^{2}$ \\ ${ }^{1}$ Prodi Studi Hubungan International, Universitas Muhammadiyah Yogyakarta, Bantul, Yogyakarta, Indonesia \\ ${ }^{2}$ Prodi Studi Agribisnis, Universitas Muhammadiyah Yogyakarta, Bantul, Yogyakarta, Indonesia
}

\begin{tabular}{l}
\hline ARTICLE INFO \\
\hline \\
Received : December, 2020 \\
Revised : February, 2021 \\
Accepted : March, 2021 \\
\hline
\end{tabular}

Keywords:

empowerment;

society;

economy;

competition.

\begin{abstract}
This community service aims to facilitate the economic sector for religious community organizations, especially towards the PRM Bangunjiwo Barat in the midst of competition from the ASEAN Economic Community $(A E C)$. This community service is important because the Indonesian people generally lack awareness of the MEA. Empowerment in the economic sector, especially those based on micro, small and medium enterprises (SMEs) is very important when the flow of global capitalism into Indonesia is boundless and unstoppable. This is in line with the transformation of the theory of International Relations (IR) from traditional issues and high politics to issues based on non-traditional and community-based low politics, especially issues of development and human security. Human security issues include health security, food security, economic security, and others. The results of this community service have succeeded in facilitating partners and it is hoped that after the service they can increase their capacity in facing global competition, especially the AEC. Several important agendas were successfully implemented in the midst of the Covid-19 pandemic, for example video editing workshops, product photos, introduction to e-commerce including helping register products in the Grab-food application, and philanthropic activities.
\end{abstract}

\section{PENDAHULUAN}

Menurut World Economic Forum (WEC) daya saing Indonesia secara global pada tahun 2019 berada pada urutan ke 50 (lima puluh) atau turun lima peringkat dibanding

\footnotetext{
* Corresponding author.

E-mail address: amaksum@gmail.com

https://doi.org/10.12928/J.spekta.v2i1.3780
} 
Vol. 2, No. 1, Juni 2021

tahun 2018. Dibandingkan dengan negara-negara di Asia Tenggara Indonesia menempati rangking 4 (empat) di bawah Singapura (peringkat 1 dunia), Malaysia dan Thailand. Secara lengkap peringkat keseluruhan negara Asia Tenggara dapat dilihat pada tabel 1.

Tabel 1 Index Daya Saing Global Negara-Negara Asia Tenggara 2019

\begin{tabular}{lcc}
\hline \multicolumn{1}{c}{ Negara } & $\begin{array}{c}\text { Peringkat Asia } \\
\text { Tenggara }\end{array}$ & Peringkat Global \\
\hline Singapura & 1 & 1 \\
Malaysia & 2 & 27 \\
Thailand & 3 & 40 \\
Indonesia & 4 & 50 \\
Brunei Darussalam & 5 & 56 \\
Filipina & 6 & 64 \\
Vietnam & 7 & 67 \\
Kamboja & 8 & 106 \\
Laos & 9 & 113 \\
Myanmar & 10 & Tidak masuk peringkat \\
\hline
\end{tabular}

Sumber: Schwab (2019)

Data tabel 1 menunjukkan bahwa daya saing Indonesia masih kalah jika dibandingkan negara-negara seperti Singapura, Malaysia, dan Thailand. Meskipun demikian Indonesia masih unggul jika dikomparasikan dengan negara lain misalnya Brunei Darussalam (56), Filipina (64), Vietnam (67), Kamboja (106), dan Laos (113). Di tengah hantaman Covid-19, upaya peningkatan daya saing menghadapi tantangan tersendiri terutama sektor ekonomi mikro atau UMKM. Padahal di mata internasional, sektor ekonomi mikro sebagai pilar penting ekonomi Indonesia (Citradi, 2020). Tingkat daya saing Indonesia yang masih kurang kompetitif tentu berdampak serius terhadap kesiapan negara dalam menghadapi Masyarakat Ekonomi ASEAN (MEA). Menurut pemerintah, peningkatan kualitas sumberdaya manusia melalui pendidikan menjadi strategi utama untuk meningkatkan daya saing bangsa serta mendorong perang pemerintah daerah (Mahardhika, 2019).

Di sisi yang lain dalam konteks kesiapan aparatur pemerintah sebuah survey juga menunjukkan bahwa Provinsi Daerah Istimewa Yogyakarta menjadi salah satu daerah yang paling siap menghadapi MEA. Hal ini bisa dilihat dalam aspek survey pemahaman aparatur Yogyakarta yang menyatakan siap menghadapi persaingan MEA. Kesiapan tersebut salah satunya ditunjukkan dengan berbagai sosialisasi yang dilakukan oleh pemerintah Yogyakarta kepada pelaku ekonomi termasuk kepada UMKM (Shinta P. \& Herdiawan T., 2020). Walau bagaimanapun, pada penelitian yang lain menunjukkan bahwa UMKM sebenarnya belum siap menghadapi MEA. Salah satu indikatornya adalah rendahnya pemahaman tentang MEA dan dinamikanya. Dalam sebuah survey yang dilakukan, menunjukkan bahwa hanya 52\% saja di kalangan UMKM yang memahami tentang MEA. Selain aspek pemahaman, salah satu penyebab lain ketidaksiapan tersebut adalah belum maksimalnya upaya promosi yang dilakukan oleh UMKM (Tribun Jogja, 2015). UMKM, memang secara nyata memberikan kontribusi positif pada pembangunan ekonomi bangsa, sehingga cukup banyak usaha oleh akademisi dan masyarakat serta pemerintah untuk meningkatkan performansi UMKM, di tengah badai Covid-19 dan serangan produk asing. Hidayat et al (2020) melakukan pengembangan dan pengelolaan untuk menuju UMKM yang lebih baik pada industri kain songket yang merupakan salah 
Vol. 2, No. 1, Juni 2021

satu kekayaan budaya di daerah Palembang, khususnya pada desa Pedu. Pada pelaksanaanya, pengembangan dan pengelolaan UMKM ini menganggap bahwa perlu adanya proteksi dan campur tangan pemerintah untuk menjaga kekayaan budaya ini tidak hilang. Pengelolaan UMKM, juga dilakukan Arfan et al (2020), terkait proteksi dari adanya praktek praktek monopoli harga, dalam kasus ini adalah monopoli harga masker akibat terjangan pandemi Covid-19 di awal tahun 2020. Pengelolaan UMKM yang baik, jelas sangat menolong dan memutus rantai monopoli, serta memberikan penguatan ekonomi pada masyarakat sekitar, dengan catatan, adanya intervensi dari akademisi atau bahkan pemerintah, agar UMKM semakin siap dengan kompetisi global nantinya.

Aspek pembangunan human capital menjadi elemen penting yang harus ditingkatkan dalam rangka menghadapi MEA (Jayanti \& Muqorobin, 2017). Hal inilah yang kemudian dimaknai dengan "pemberdayaan masyarakat" dalam meningkatkan daya saing bangsa termasuk UMKM. Pemberdayaan dalam bidang e-commerce salah satu aspek yang bisa meningkatkan daya saing UMKM. Sangat sedikit peneliti yang mengkaji pemberdayaan masyarakat khusus terkait e-commerce terutama di Daerah Istimewa Yogyakarta. Sebagian peneliti fokus terhadap peningkatan kapabilitas mitra UMKM Rempeyek di Desa Bener, Tegalrejo, Yogyakarta dalam melakukan inovasi produk (Ningsih, Kintoko, \& Putri, 2020; Utami \& Prasetyo, 2020). Ada penelitian yang fokus untuk memberdayakan masyarakat dalam memaksimalkan e-commerce yaitu Erwinsyah, Atmojo, and Pratiwi (2018) yang mendampingi masyarakat membuat akun belabeliku.com di Kulonprogo, Yogyakarta dan (Handayani, Sari, Widharto, \& Raharjo, 2019) membantu pembuatan website UMKM Batik Marenggo Natural Dyes di Berbah, Sleman, Yogyakarta. Dari aspek inovasi produk, maka analisis kajian Ningsih et al. (2020) layak untuk diaplikasikan pada pengabdian masyarakat daerah lainnya. Sedangkan untuk upaya marketing berbasis e-commerce maka kajian Handayani et al. (2019) sangat penting untuk dipraktekkan. Dari kajian-kajian di atas, belum ada yang membahas secara khusus tentang problematika e-commerce khususnya di Desa Bangunjiwo, Kasihan, Yogyakarta yang memiliki potensi UMKM misalnya sentra industri patung, Ayam Joper (Jowo Super), kerajinan tangan dan lain-lain. Berdasarkan observasi di lapangan, pemberdayaan masyarakat yang selama ini berjalan di Bangunjiwo masih kurang. Hanya beberapa inisiasi misalnya meningkatkan kemampuan Bahasa Inggris namun tidak terpublikasikan secara ilmiah. Kebanyakan produk hasil industri diambil langsung oleh para tengkulak kelas atas. Apalagi fokus pemberdayaan berbasis organisasi kemasyarakatan, juga belum ada karya yang spesifik membahasnya.

Oleh karena itu, dengan mempertimbangkan latar belakang di atas, maka penting untuk dilakukan pemberdayaan masyarakat di Desa Bangunjiwo, Kecamatan Kasihan, Bantul, Yogyakarta. Tepatnya, lokasi pengabdian dan pemberdayaan masyarakat adalah pada Pimpinan Ranting Muhammadiyah (PRM) Bangunjiwo Barat yang membina beberapa UMKM dalam bidang makanan dan peternakan. Upaya yang dilakukan oleh PRM Bangunjiwo Barat harus didukung dan merupakan sebuah upaya pembuktian komitmen kebangsaan Muhammadiyah dalam pemberdayaan ekonomi bangsa khususnya di level masyarakat paling bawah. Secara spesifik, permasalahan mitra adalah:-

1. Belum tertatanya sistem informasi dan manajemen dalam operasional bisnis,

2. Belum mempunyai platform untuk melakukan promosi secara online, dan

3. Belum maksimalnya pemanfaatan sarana dan prasarana yang tersedia dalam menunjang kegiatan produktif lainnya baik berbasis ekonomi maupun kemasyarakatan-keagamaan 
Vol. 2, No. 1, Juni 2021

\section{METODE PELAKSANAAN}

Salah satu tujuan pokok pengabdian masyarakat ini adalah pemberdayaan masyarakat agar lebih maju, produktif, dan berkualitas dibanding sebelumnya (Suharto, 2017). Agenda fasilitasi menjadi program penting dalam rangka untuk mencapai tujuan tersebut. Pada akhirnya, adanya fasilitas tersebut diharapkan masyarakat menjadi lebih mandiri dan tidak tergantung dengan siapapun (Korten, 1990). Hal ini umum terjadi pada masyarakat di negara-negara Dunia Ketiga yang menuntut resilience (ketahanan) di tengah berbagai masalah negara (Hope, 1983). Ketahanan ini penting sebagai upaya bertahan akibat dampak globalisasi dan perdagangan internasional yang seringkali merugikan masyarakat kecil (Fukuda-Parr, 2003). Oleh karena itu, untuk mewujudkan upaya pemberdayaan masyarakat khususnya di bawah organisasi PRM Bangunjiwo Barat, maka pengabdian ini akan melaksanakan tahapan kegiatan sebagaimana berikut:-

1. Observasi permasalahan mitra melalui kunjungan ke lokasi mitra dan melakukan diskusi dengan pengurus dan manajemen mitra.

2. Literasi tentang MEA dan tantangan yang harus dihadapi masyarakat terutama kelompok UMKM.

3. Pendampingan mitra melalui serangkaian kegiatan untuk peningkatan manajemen dan strategi promosi berbasis online.

4. Rencana berkelanjutan atas inisiasi yang sudah dilakukan selama pendampingan terhadap mitra.

Kedaan mitra dapat dilihat dari kondisi aspek geografis dan aspek kelembagaan.

a. Aspek Geografis

Pengabdian ini dilaksanakan di Dukuh Lemahdadi, Desa Banguniwo, Kasihan, Bantul, Yogyakarta khususnya di bawah Persyarikatan Muhammadiyah. Lokasi pengabdian. Lokasi pengabdian tersebut berjarak $4,1 \mathrm{Km}$ dari Universitas Muhammadiyah Yogyakarta di Jl. Brawijaya, Kasihan, Bantul, Yogyakarta sebagaimana peta berikut.

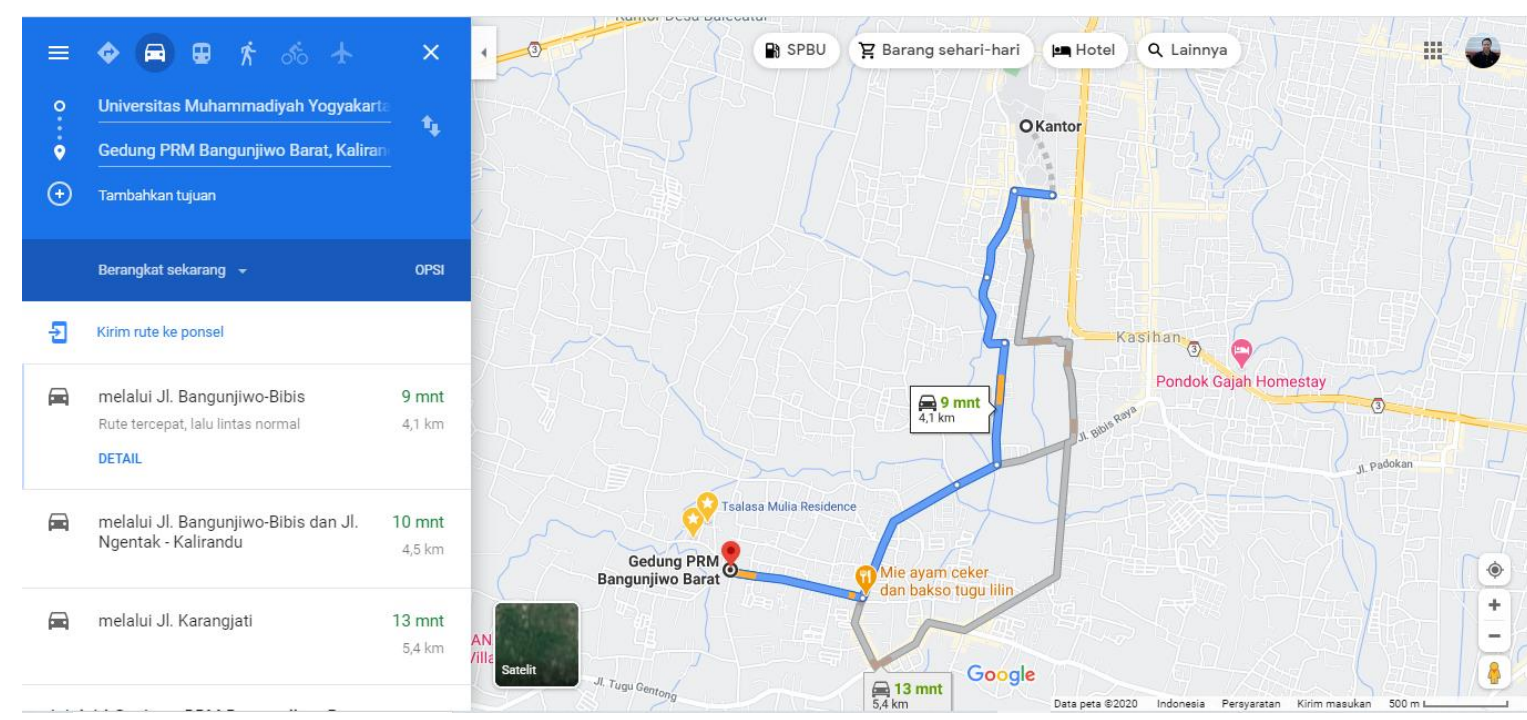

Gambar 1. Lokasi pengabdian masyarakat

Adapun detail lokasi pengabdian seperti berikut:-

Batas Utara : Desa Tamantirto

Batas Selatan : Desa Guwosari

Batas Barat : Desa Triwidadi 
Vol. 2, No. 1, Juni 2021

Batas Timur : Desa Tirtonirmolo

Sebagian besar wilayah Desa Bangunjiwo, berdasarkan tata guna lahan 52\% berupa tegal, perkebunan dan hutan. Sedangkan sisanya, 35\% untuk pemukiman dan $13 \%$ untuk persawahan. Desa Bangunjiwo juga merupakan sentra kerajinan seperti patung, cindera mata dan lain-lain. Pusat Kesehatan Masyarakat (PUSKESMAS) Kecamatan Kasihan terletak di kawasan ini tepatnya di Jl. Bibis Km 8, Bangunjiwo.

b. Aspek Kelembagaan

Di Dukuh Lemahdadi berdiri Pimpinan Ranting Muhammadiyah (PRM) Bangunjiwo Barat dipimpin oleh Agus Mulyono BS. Ada beberapa 'amal usaha' atau badan usaha yang dikelola oleh PRM Bangunjiwo Barat seperti MTS Muhammadiyah Bangunjiwo, SMK Muhammadiyah Bangunjiwo, MI Unggulan Lemahdadi dan lainlain. Adapun badan usaha yang berbasis ekonomi PRM Bangunjiwo Barat membina UMKM yaitu Jus Arena dan budidaya Ayam Joper (Jowo Super).

\section{HASIL DAN PEMBAHASAN}

Pada pelaksanaan pendampingan ini, fokus pengabdian diarahkan kepada peningkatan kapabilitas e-commerce dan skill lain di bidang teknologi informasi (TI) organisasi dan badan usaha ekonomi. Agenda ini penting bagi memastikan organisasi dan UMKM ter-upgrade kemampuan TI dan e-commerce agar mampu bersaing dalam kompetisi ASEAN. Hal ini selaras dengan masalah-masalah di berbagai negara terkait dengan rendahnya daya saing produk dan sumber daya manusia yang merupakan masalah penting dalam isu-isu kemanana manusia (human security).

Pada awal observasi di lapangan, mendapati bahwa persoalan TI dan e-commerce menjadi masalah umum yang dihadapi meskipun secara umum masyarakat sudah mengenal tentang TI. Namun, masalah tersebut masih saja muncul di tengah berbagai masalah lainnya misalnya kemampuan ekonomi dan minimnya infrastruktur pendukung. Hal ini sebagaimana terungkap selama visitasi terhadap mitra berikut berbagai masalah, alternatif pemecahan, dan inisiasi oleh tim pengabdian.

a. Pengenalan TI dan e-commerce

Pemasaran produk secara online melalui aplikasi Gojek bertujuan untuk memperluas pemasaran produk dengan menggunakan platform media sosial dan market place yang telah dibuat. Pemasaran produk ini akan lebih fokus untuk penjualan lebih ranah yang lebih luas, dan juga menambah pendapatan dan tidak terpaku pada penjualan offline. Tim pengabdian menjadikan pemasaran produk secara online sebagai program pokok karena berdasarkan need assessment yang telah dilaksanakan saat observasi menunjukan bahwa mitra membutuhkan pendampingan dan pelatihan dalam pemasaran produk secara online melalui aplikasi Gojek.

Dalam kegiatan ini, pihak mitra juga memperkenalkan berbagai produk yang dijual di toko kepada tim pengabdian. Hal ini bertujuan untuk mempermudah menjalankan kegiatan selanjutnya yang berkaitan dengan penjualan produk secara online. Mitra juga mengaku kurang memahami penjualan secara online dan belum ada karyawan khusus yang menangani pemasaran secara online tersebut. Namun, mitra ingin memasarkan produk-produknya lebih luas. Karena penjualan lokal kurang diminati, jika ada hanya pembelian dalam skala kecil (eceran). Selama ini penjualan terbesar datang dari pembelian secara partai atau pembelian 20 pcs keatas. Dari permasalahan tersebut tim memperkenalkan media sosial kepada mitra pada tanggal 15 Januari 2021 bertempat di Jus Arena, di Lemahdadi, Bangunjiwo, Bantul. Faktor pendukung kegiatan ini yaitu mitra ada kemauan untuk memasarkan produk- 
Vol. 2, No. 1, Juni 2021

produknya secara online. Dengan adanya pengenalan media sosial ini, mitra dapat merealisasikan pemasaran secara online.

Dalam konteks pendampingan organisasi tim pengabdian berupaya menelaah apa yang bisa dipecahkan dari permasalahan mitra di bidang TI di tengah pandemic Covid19. Beberapa poin penting adalah perlunya pelatihan pembuatan video pembelajaran bagi guru-guru di lingkungan PRM Bangunjiwo Barat. Sedangkan untuk pemberdayaan UMKM, tim pengabdian melakukan pendampingan budidaya Ayam Joper (Jowo Super) yang dikelola di bawah PRM Bangunjiwo Barat melalui Angkatan Muda Muhammadiyah (AMM). Pada observasi yang dilakukan beberapa kendala muncul misalnya terkait pemasaran/ marketing agar menjadi menarik. Selain itu, hasil ternak ayam perlu diolah menjadi produk yang bervariasi termasuk kemungkinan pembuatan "frozen food". AMM tidak saja bergerak dalam pemberdayaan ekonomi, namun juga filantofi yang menyasar keluarga tidak mampu di sekitar lokasi pengabdian. Hal ini tentu sangat penting untuk didukung agar berbagai capaian yang didapatkan melalui pemberdayaan ekonomi tetap memperhatikan kelompokkelompok rentan di tengah kesenjangan ekonomi.
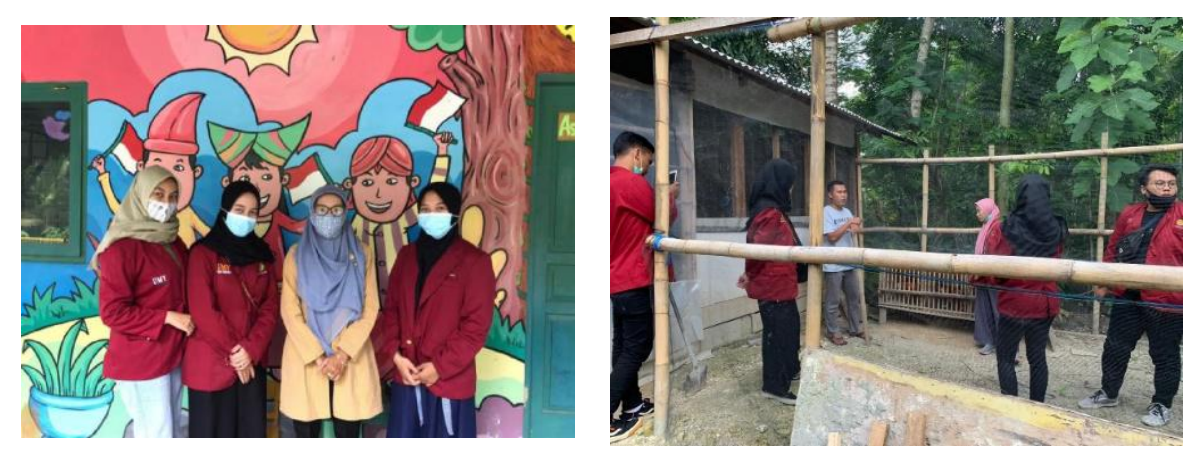

Gambar 2. Observasi mitra

b. Realisasi program berbasis IT, e-commerce, dan filantrofi

1. Pelatihan editing video guru-guru TK 'Aisyiyah Bangunjiwo Barat

Pelatihan atau workshop editing video merupakan salah satu jawaban penting bagi mengatasi kendala terkait pembuatan video pembelajaran di tengah pandemi Covid-19. Oleh karenanya, tim pengabdian menginisiasi "workshop editing video pembelajaran bagi guru-guru TK 'Aisyiyah se-Bangunjiwo Barat." Kegiatan ini dilaksanakan pada tanggal 3 dan 5 Februari 2021 bertempat di TK ABA Lemahdadi, Bangunjiwo. Adanya kegiatan tersebut mendapatkan respon dan antusiasme yang sangat dari guru-guru di bawah pembinaan Pengurus Ranting Aisyiyah (PRA) Bangunjiwo Barat. Pada workshop dua hari ini, peserta disuguhkan materi dan praktik langsung editing video oleh instruktur dari Universitas Muhammadiyah Yogyakarta. 

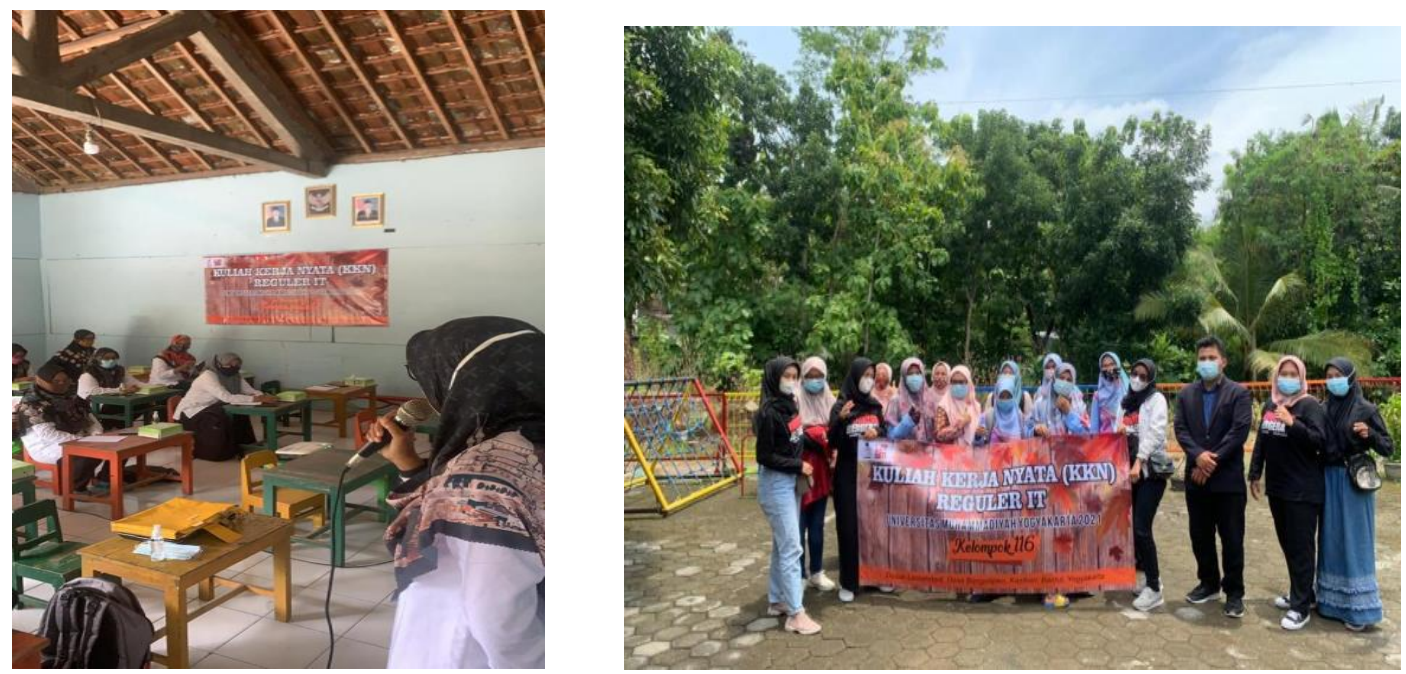

Gambar 3. Program workshop editing video pembelajaran

2. Pemberdayaan UMKM melalui e-commerce dan filantrofi

a) Foto Produk

Pada kegiatan ini tim pengabdian melaksanakan inisiasi pembuatan foto produk Jus Arena agar menarik untuk didaftarkan di aplikasi Grab-food dan Gofood. Hal ini akan menarik pembeli dalam melihat dan memilih produk-produk yang dijual oleh mitra. Selain itu, tampilan yang menarik akan sangat membantu Jus Arena dalam hal menampilkan dan memasarkan produk menjadi lebih luas dan marketable.
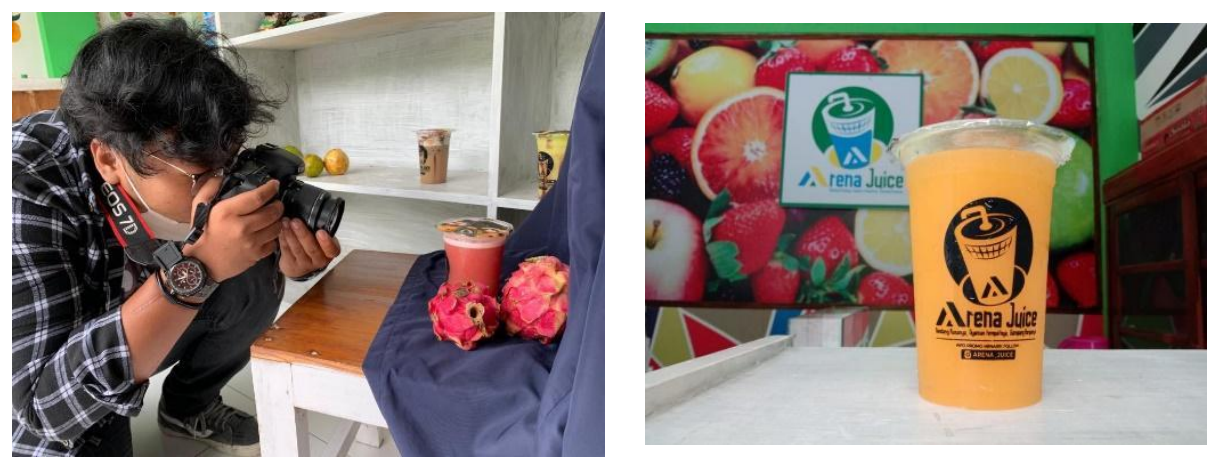

Gambar 4. Pengambilan foto produk

b) Membantu pembuatan dan pendaftaran akun Grab/Gojek

Setelah melakukan sesi foto produk, tim pengabdian melakukan survey untuk memulai mendaftarkan ke aplikasi Go-food atau Grab-food bagi Jus Arena. Pada proses pendaftaran aplikasi ini, akses jaringan internet menjadi sangat penting. Dengan segala keterbatasan yang ada, tim pengabdian berusaha memotivasi Jus Arena agar lebih maju dan berkembang. Berlokasi di Gedung yang sudah menjadi milik PRM Bangunjiwo Barat, kedepan diharapkan Jus Arena tidak saja bergerak dalam bidang minuman sehat namun produk harus lebih variatif. Selain itu, tim 
Vol. 2, No. 1, Juni 2021

pengabdian juga berupaya untuk memberikan informasi tentang bahan baku utama produksi Jus Arena yaitu buah-buahan. Oleh karenanya, tim pengabdian melakukan survey ke beberapa pasar buah untuk dibuatkan daftar harga yang bisa menjadi referensi Jus Arena menentukan harga dan pilihan stok buah.

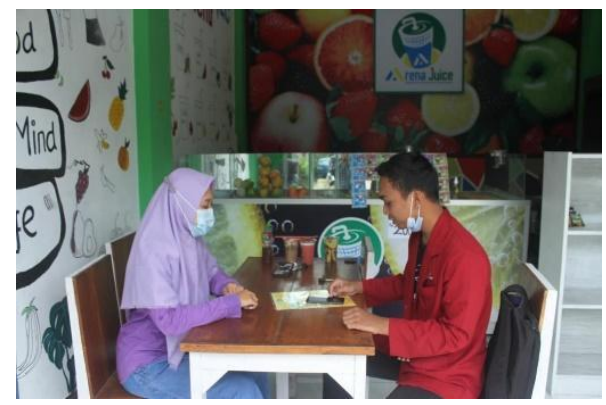

Gambar 5. proses pendaftaran Grab Food

c) Program filantropi dan pemberdayaan ekonomi

UMKM Ayam Joper yang dikelola AMM Bangunjiwo Barat, pada dasarnya tidak saja bergerak dalam bidang ekonomi khususnya budidaya ayam. Namun, secara simultan juga menggerakkan roda kehidupan sosial dan keagamaan masyarakat melalui serangkaian program. Misalnya program Serambi Dakwah dan Program Filantrofi. UMKM Ayam Joper merupakan terobosan penting dan mempunyai visi jangka panjang. Target budidaya Ayam Joper ke depan adalah para pensiunan terutama anggota PRM Bangunjiwo Barat agar tetap produktif di masa pensiun. Dalam masa perintisan ini, adanya pengabdian masyarakat sangat bermanfaat terutama dalam rangka menumbuhkan ide dan gagasan ke depan agar tetap optimis di masa pandemi Covid-19.

Selain itu, dengan menggandeng beberapa donator, Serambi Dakwah melakukan survey terhadap masyarakat yang potensial menerima bantuan. Pada kesempatan ini, tim pengabdian melakukan kolaborasi untuk menyalurkan bantuan kepada masyarakat kurang mampu sekitar lokasi pengabdian. Hasilnya, sejumlah bantuan paket sembako berhasil disalurkan kepada yang berkah menerimanya.
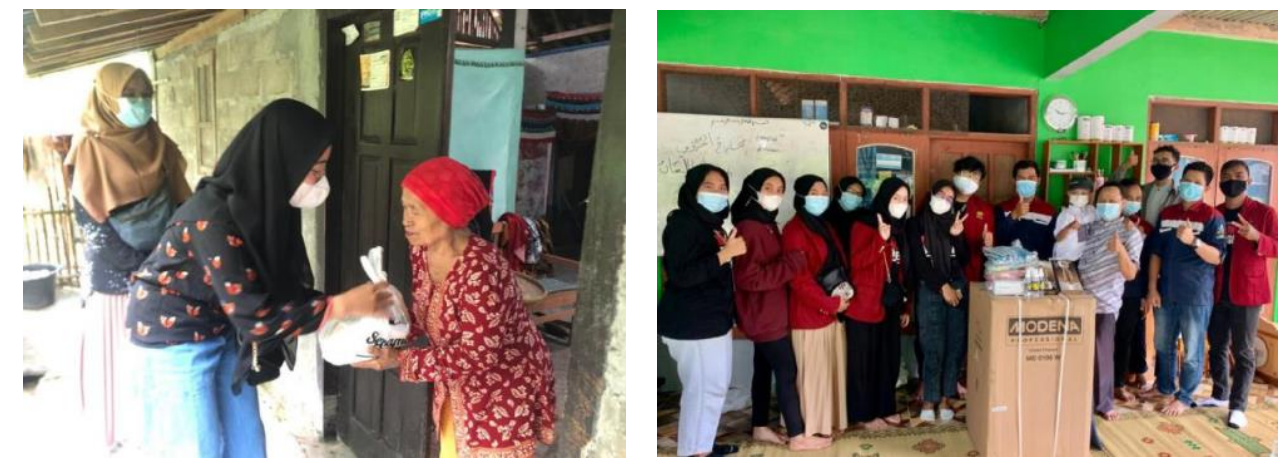

Gambar 6. Program filantropi dan pemberian bantuan kepada UMKM Ayam Joper 
Vol. 2, No. 1, Juni 2021

\section{KESIMPULAN}

Pelaksanaan pengabdian pada periode ini tampak sangat berbeda dan menantang karena dilaksanakan di tengah pandemi Covid-19. Tim pengabdian tentunya dituntut untuk bisa melaksanakan pengabdian dengan baik namun pada saat yang sama harus menerapkan protokol kesehatan. Di tengah berbagai kendala ini, tim pengabdian berhasil melaksanakan pengabdian dengan mengagendakan beberapa kegiatan. Tujuannya adalah untuk meningkatkan kapasitas masyarakat/mitra yaitu ormas Persyarikatan Muhammadiyah di Bangunjiwo Barat dan UMKM berbentuk budidaya Ayam Joper dan Jus Arena dalam menghadapi MEA. Pengenalan e-commerce dan TI menjadi penting selaras dengan tema pengabdian pada periode ini. Mitra dalam hal ini menyambut baik inisiasi pengabdian yang berbasis TI. Oleh karenanya, pengabdian berhasil melaksanakan agenda misalnya workshop video editing untuk pembelajaran (untuk guruguru di bawah PRA 'Aisyiyah), foto produk (UMKM Jus Arena), pengenalan $e$ commerce (UMKM Ayam Joper) termasuk mendaftarkan produk untuk dijual dalam aplikasi Grab-food (UMKM Jus Arena), dan kegiatan filantrofi (UMKM Ayam Joper dan Serambi Dakwah). Akhirnya, adanya pengabdian ini, disambut sangat baik oleh mitra dan mengharapkan kedepan agenda serupa bisa dilaksanakan demi kesinambungan program.

\section{UCAPAN TERIMA KASIH}

Penulis menyampaikan terima kasih dan penghargaan setinggi-tingginya kepada Universitas Muhammadiyah Yogyakarta yang telah memberikan dukungan pendanaan untuk pengabdian ini melalui skema KKN-PPM. Penulis juga berterima kasih kepada dua reviewer yang telah memberikan masukan penting untuk draft ini agar semakin berkualitas. Kesalahan dalam penulisan ini adalah tanggung jawab penulis dan argumen yang ditampilkan adalah murni dari pendapat penulis dan tidak mencerminkan pandangan institusi Universitas Muhammadiyah Yogyakarta.

\section{DAFTAR PUSTAKA}

Arfan, R., Puspita, D., Akbar, I., Ambartiasari, G., \& Minarwati. (2020). Peran ukm dalam menstabilkan harga masker sebagai bentuk pencegahan penyebaran covid-19 di banda aceh. SPEKTA Jurnal Pengabdian Kepada Masyarakat: Teknologi Dan Aplikasi, 1(1), 31-34.

Citradi, T. (2020). Ada Cerita Sedih Ekonomi Loyo di Balik Turunnya Daya Saing RI. CNBC Indonesia, $18 \quad$ Juni Retrieved from https://www.cnbcindonesia.com/news/20200618153002-4-166343/ada-ceritasedih-ekonomi-loyo-di-balik-turunnya-daya-saing-ri

Erwinsyah, R., Atmojo, M. E., \& Pratiwi, V. P. (2018). Efektivitas Belabeliku.Com Dalam Pemberdayaan Masyarakat Berbasis E-Commerce Kabupaten Kulon Progo Tahun 2018. Jurnal Moderat, 6(3), 501-512.

Fukuda-Parr, S. (2003). New Threats to Human Security in the Era of Globalization. Journal of Human Development, 4(2), 167-179. doi:10.1080/1464988032000087523

Handayani, N. U., Sari, D. P., Widharto, Y., \& Raharjo, M. F. M. (2019). Peningkatan Efisiensi Produksi dan Omzet Penjualan UMKM Batik Melalui Pemanfaatan Sistem Informasi E-Commerce UMKM Batik Marenggo Natural Dyes. Jurnal Pasopati, 1(1), 16-21.

Hidayat, Gunadi, Arlangga, L., \& Yulianti, F. (2020). Pengelolaan Kain Tenun Songket Khas Palembang di desa Pedu Kabupaten Jejawi Kecamatan Ogan Komering Ilir 
Vol. 2, No. 1, Juni 2021

(OKI). SPEKTA Jurnal Pengabdian Kepada Masyarakat: Teknologi Dan Aplikasi, 1(1), 21-30.

Hope, K. R. (1983). Self-reliance and participation of the poor in the development process in the Third World. Futures, 15(6), 455-462.

Jayanti, P. T., \& Muqorobin, M. (2017). Analisis Strategi dan Program Peningkatan Daya Saing Pada Industri Unggulan Provinsi Jawa Tengah Dalam Menghadapi Masyarakat Ekonomi ASEAN (MEA). Jurnal Ekonomi \& Studi Pembangunan, 18(1), 52-61.

Korten, D. C. (1990). Getting to the 21st Century: Voluntary Action and the Global Agenda. Virginia: Kumarian Press.

Mahardhika, L. A. (2019). Genjot Daya Saing, Indonesia Perbaiki Kualitas SDM. Bisnis, $11 \quad$ Oktober. Retrieved from https://ekonomi.bisnis.com/read/20191011/9/1158109/genjot-daya-saing-indonesiaperbaiki-kualitas-sdm

Ningsih, S. C., Kintoko, \& Putri, P. H. (2020). Inovasi Kemasan dan Perluasan Pemasaran Usaha Rempeyek di Yogyakarta. Dinamisia: Jurnal Pengabdian Kepada Masyarakat, 4(1), 6-11.

Schwab, K. (2019). The Global Competitiveness Report 2019. Geneva: World Econmic Forum.

Shinta P., D., \& Herdiawan T., D. (2020). Pemerintah Daerah dan Masyarakat Ekonomi ASEAN Hubungan Pusat-Daerah di Era Integrasi Kawasan. Yogyakarta: ASEAN Studies Center, Fakultas Ilmu Sosial dan Ilmu Politik, Universitas Gadjah Mada.

Suharto, E. (2017). Membangun Masyarakat memberdayakan Rakyat: Kajian Strategis Pembangunan Kesejahteraan Sosial dan Pekerjaan Sosial. Bandung: Refika Aditama.

Tribun Jogja. (2015). UKM Belum Siap Hadapi MEA. Tribun Jogja, 8 Maret.

Utami, F., \& Prasetyo, I. (2020). Pemberdayaan Masyarakat Melalui Program Pengabdian Masyarakat dalam Meningkatkan Kemampuan Pemasaran Produk. Journal of Millennial Community, 2(1), 20-27. 